O léxico das comunidades indígenas do Ceará na designação de doenças: reflexões para a construção de vocabulário controlado

\title{
O léxico das comunidades indígenas do Ceará na designação de doenças: reflexões para a construção de vocabulário controlado ${ }^{1}$
}

Virginia Bentes Pinto ${ }^{I}$

https://orcid.org/0000-0003-1283-8292

Henry de Holanda Campos ${ }^{I I}$

https://orcid.org/0000-0001-8882-364X

Maria do Socorro Aragão ${ }^{I I I}$

https://orcid.org/0000-0002-8079-6058

Cristina da Costa Ribeiro ${ }^{I V}$

https://orcid.org/0000-0002-3782-3233

${ }^{I}$ Universidade Federal do Ceará, CE, Brasil.

Pós-doutorado em Filosofia.

${ }^{\text {II }}$ Universidade Federal do Ceará, CE, Brasil.

Docente do Departamento de Medicina Clínica.

III Universidade Federal da Paraíba, PB, Brasil..

Docente da UFPB.

${ }^{I V}$ Universidade Federal do Ceará, CE, Brasil

Bibliotecária.

http://dx.doi.org/10.1590/1981-5344/3819

1 Parte dos resultados da pesquisa intitulada "Proposta de construção de um vocabulário de nomes populares das doenças e sua relação com a terminologia da área da saúde na perspectiva de melhorar a comunicação no contexto do 'Programa Mais Médicos'". Chamada Apoio a Projetos de Pesquisa/MCTI/CNPQ/Universal 14/2. 
Apresenta os resultados da pesquisa cujo objetivo é construir um Vocabulário Controlado de Nomes Populares de Doença (VCNPD) a partir do léxico utilizado pelas comunidades indígenas do Ceará, estabelecendo-se as relações com a terminologia de especialidade da saúde. É uma pesquisa aplicada, sendo o estudo empírico feito em quatro etapas: entrevista com os líderes e pajés das comunidades indígenas Tapebas, Pitaguarys e JenipapoKanindés, localizadas no Estado do Ceará; mapeamento dos nomes populares das doenças em fontes populares e terminológicas especializadas; construção do protótipo do VCNPD com as palavras mapeadas especificando-se as relações com a terminologia da CID-10. Os resultados evidenciam 355 (trezentas e cinquenta e cinco) palavras pertencentes ao léxico das comunidades investigadas. 0 cotejamento expressa pouca coincidência entre as palavras que nominam as doenças entre os povos investigados - somente 41 (quarenta e uma), sendo que 9 (nove) se duplicam nas três comunidades, 15 (quinze) entre os Tapebas e os Pitaguarys, 6 (seis) entre Tapebas e Jenipapo-Kanindés; 11 (onze) coincidem entre os Pitaguarys Jenipapo-Kanindés. Conclui-se que a construção do VCNPDse reveste de grande importância, tanto para a preservação da memória lexical dessas comunidades como também para favorecer a comunicação entre esses povos e os profissionais da saúde, nas ações de cuidados dedicadas a esses cidadãos.

Palavras-chave: Vocabulário controlado; vocabulário controlado de nomes populares de doenças; nomes populares de doenças; memória do léxico em saúde.

\section{The lexicon of the indigenous communities of Ceará in the designation of diseases: reflections for the construction of controlled vocabulary}


We present here the results of a research whose objective is to construct a Controlled Vocabulary of Popular Disease Names (CVPDN) based on the lexicon used by the indigenous communities of Ceará, by establishing relationships with the specialized terminology of the Health area. This is an applied research, with the empirical study being conducted in four stages: interview with the leaders and shamans of the Tapebas, Pitaguarys and Jenipapo-Kanindés indigenous communities, located in the state of Ceará; Mapping of the popular diseases' names in popular and specialized terminological sources; Construction of the CVPDN prototype with the mapped words showing the relationships with the ICD-10 terminology. The results show 355 (three hundred and fifty-five) words belonging to the lexicon of the investigated communities. Comparison of results presents little coincidence between the words that nominate diseases among the people investigated - only 41 (forty-one) with 9 (nine) being repeated in the three communities; 15 (fifteen) repeating themselves between Tapebas and Pitaguarys communities; 6 (six) between Tapebas and Jenipapo-Kanindés communities; 11 (eleven) coincide between Pitaguarys and Genipapokanindés communities. We conclude that the construction of the CVPDN is of great importance, both for the preservation of the lexical memory of these communities and also to enable communication between these peoples and health professionals and in the care actions of those citizens.

Keywords: Controlled vocabulary; Controlled Vocabulary of Popular Disease Names; Popular diseases name; Memorial of Health Lexicon.

\section{Introdução}


Ao longo da história da humanidade, o léxico de uma comunidade ou de um grupo social reflete, de maneira geral, a representação do conhecimento e de sua cultura, sendo adotado para nominar as coisas e os objetos do mundo. Entretanto, com a dinamicidade da sociedade, ele também ganha outros matizes, porém, as raízes permanecem no âmago das culturas. Isso ocorre porque, conforme Paula (2007, p. 54), ao mesmo tempo que o léxico

[...] consolida o saber de um povo e o resguarda como um baú na memória dos falantes é também a face linguística mais dinâmica de expressão desse saber, uma vez que os saberes se atualizam e se interpenetram constantemente.

Em que concerne à especialização dos domínios de conhecimentos, as palavras do léxico tomam a nominação de termos que formam as chamadas linguagens de especialidades. Esses termos são a base para a construção de vocabulários controlados (VC) que desempenham importante papel na tradução das pistas identificadas e selecionadas na representação indexal de documentos tendo em vista a possibilidade de redução das polissemias muito presentes no processo de comunicação em linguagem natural.

Embora esteja o VC no cerne das linguagens de especialidades, fazse essencial não esquecer que, no âmbito dos falares do cotidiano do cidadão, tal vocabulário deve ser, igualmente, pensado com a finalidade de favorecer a comunicação entre os sujeitos com culturas e repertórios linguísticos diferentes, como é o caso, por exemplo, dos diálogos entre médicos e pacientes tanto no ato da anamnese como das evoluções clínicas redigidas por esses profissionais ou aqueles da área de enfermagem ou outros. Ratificando nossa ideia, Biderman (1981, p. 132) argumenta que "[...] se considerarmos a dimensão social da língua, podemos ver no léxico o patrimônio social da comunidade por excelência, juntamente com outros símbolos da herança cultural". A autora continua seu pensamento dizendo que "Dentro desse ângulo de visão, esse tesouro léxico é transmitido de geração a geração como signos operacionais, por meio dos quais os indivíduos de cada geração podem pensar e exprimir seus sentimentos e ideias $[\ldots]^{\prime \prime}$. Desse modo, podemos ratificar que o léxico se configura em um tipo de representação do conhecimento no âmbito das comunidades e grupos sociais.

É, pois, nessa perspectiva que esta pesquisa foi desenvolvida, pautando-se na seguinte questão: Como estruturar um protótipo de Vocabulário Controlado de Nomes Populares de Doenças (VCNPD), a partir do léxico utilizado pelas comunidades indígenas do Ceará, estabelecendo- 
se as relações com a Classificação Internacional de Doenças e Problemas Relacionados à Saúde (CID)?

A nossa intenção maior para a construção dessa proposta de vocabulário controlado não visa, necessariamente, contribuir para o processo de representação indexal, organização e recuperação de informação registrada em documentos, analógicos e/ou digitais. Porém, particularmente, em outras duas perspectivas: a primeira, visa contribuir para redução das interferências no processo de comunicação em ambientes intercultural e multilingual como é o caso da equipe multiprofissional da saúde e comunidades ou grupos sociais, no momento das ações de cuidados de pessoas que buscam as instituições de saúde. A segunda, na perspectiva do resgate e da preservação do léxico como memória e patrimônio cultural das comunidades indígenas cearenses.

O objetivo geral desta pesquisa é construir um protótipo de Vocabulário Controlado de Nomes Populares de Doenças (VCNPD) a partir do léxico utilizado pelas comunidades indígenas do Ceará, tendo em vista estabelecer relações com a terminologia de especialidade da saúde. Os objetivos específicos da pesquisa são:

a) Mapear, mediante o contato com as comunidades indígenas cearenses, os nomes populares que nominam as doenças ocorrentes ou não nessas comunidades;

b) Cotejar os nomes populares das doenças com as fontes populares especializadas tendo em vista compreender o significado do léxico mapeado;

c) Construir o protótipo do VCNPD, apoiando-nos nas normas da ANSI/NISO (2005)-Z39.19-2005 (R2010) e em Smit; Kobashi (2003), a fim de estabelecer relações com a CID-10;

É uma pesquisa exploratório descritiva cuja análise sustenta-se no método funcionalista e pauta-se nos dados coletados no estudo empírico, tanto nas fontes linguísticas dedicadas ao mapeamento dos nomes populares de doenças como também na CID-10. Foi realizada, também, uma pesquisa de campo nas comunidades selecionadas, mediante a observação e aplicação de entrevistas não estruturadas a fim de se obter mais informações sobre os nomes populares que nomeiam as doenças e verificar a ocorrência de univocidade de entendimento entre os membros das referidas comunidades. Essas duas técnicas foram realizadas em diferentes etapas do desenvolvimento do projeto "Proposta de construção de um vocabulário de nomes populares das doenças e sua relação com a terminologia da área da saúde na perspectiva de melhorar a comunicação no contexto do 'Programa Mais Médicos'", no contexto do Universal CNPQ - Processo-456624/2014-7. Foram entrevistadas as comunidades Tapebas, Pitaguarys e Jenipapo-Kanindés. O estudo empírico foi realizado 
nos meses de maio de 2016, agosto, novembro e dezembro de 2017 e janeiro de 2018 .

\section{Vocabulário controlado}

Nos campos da Biblioteconomia e da Ciência da Informação, os vocabulários controlados (VC) são conceituados como listas de termos ou outras unidades léxicas padronizadas e com relações de equivalência, hierárquicas e associativas, sendo utilizados no processo de representação indexal, visando à organização, à busca e à recuperação da informação. Eles estão inseridos no domínio dos Knowledges Organization Systems (KOS) e são denominados Linguagens Documentárias, controladas ou de indexação.

Para Currieret al. (2005, p. 9) o vc "[...] consiste em uma lista preestabelecida de termos ou cabeçalhos em que cada um tem um significado atribuído" e as relações existentes entre eles. O modo como são definidas essas relações em um vc "[...] variará em grau de complexidade de acordo com o propósito do vocabulário, desde simples listas planas ordenadas alfabeticamente, até ontologias com relacionamentos ricamente definidos".2 Conforme Hedden (2008, p.1) os vocabulários controlados são chamados assim, "[...] porque somente os termos da lista podem ser usados para a área de assunto coberta por ele [...]". E, também, devido ao modo "[...] como os termos podem ser adicionados à lista". Embora essa questão da padronização seja a tônica do VC, pensamos que ele também pode trazer contribuições ímpares para aqueles interessados no tema da pesquisa e, particularmente, no ambiente do ciberespaço a exemplo da web2.0.

O American National Standards Institute (ANSI) e a NationalInformation Standards Organization (NISO) argumentam que o propósito dos vocabulários controlados "é fornecer um meio para organizar a informação. Através do processo de atribuição de termos selecionados para descrever documentos e outros tipos de objetos de conteúdo". Para tanto, ele serve a quatro propósitos: Tradução:converte linguagem natural para a linguagem controlada; Consistência: padroniza os termos utilizados; indica relações e as relações semânticas entre os termos; Estabelece rótulos em um sistema de navegação orientando os usuários nas estratégias de busca; Recuperação: serve como um auxiliar de pesquisa na localização de objetos de conteúdo (ANSI/NISO, 2005, p.

\footnotetext{
2"Prescribed list of terms or headings each one having an assigned meaning. [...] The way a controlled vocabulary defines the relationships between these terms or headings will vary in degree of complexity according to the purpose of the vocabulary, from simple alphabetically arranged flat lists to ontologies with richly defined relationships" (Currieret al., 2005:9)
} 
10. Tradução nossa). ${ }^{3}$ Entretanto, entendemos que além desses propósitos, um VC também é uma fonte de informação de fundamental importância para a preservação da memória dos léxicos das comunidades.

Embora voltados para a terminologia de especialidades, na atualidade do mundo digital, defendemos que os vocabulários controlados possam ser estruturados com o léxico das comunidades e dos grupos sociais. Istoporque, nesse mundo e em outros ambientes, os sujeitos pertencentes a esses seguimentos se expressam com esse léxico que reflete a sua memória e seu patrimônio cultural e, portanto, vai sendo incorporado por outras comunidades, inclusive aquelas que utilizam as linguagens de especialidades. Entretanto, se não tivermos inserido nesse ambiente um vocabulário com esse léxico e suas devidas relações, as interferências no processo de comunicação estarão muito mais presentes. $\mathrm{E}$, no caso de áreas como as Ciências da Saúde, podem contribuir para o não entendimento entre os sujeitos envolvidos nesse processo.

Na mesma direção, Harpring (2010, p.1) nos diz que, tratando-se de arte e de patrimônio cultural,

Um vocabulário controlado é uma ferramenta padronizada de informação que contém palavras e frases usadas para se referir a ideias, características físicas, pessoas, lugares, eventos, assuntos e muitos outros conceitos.

Por isso, "cada vez mais as comunidades têm feito uso de vocabulários controlados e outros padrões visando o acesso à informação, anteriormente registradas em arquivos em papel ou isoladas em sistemas locais" e, atualmente, na Internet e no sistema web. Destarte, nos ambientes virtuais e supostamente abertos, a proliferação do léxico de várias línguas é uma constatação, não obstante os vários saberes. Citamos o caso dos nomes populares das doenças que, mesmo não sendo conhecidos, quando falados ou digitados em território do ciberespaço já torna evidente que esse léxico não está excluído desse ambiente. Somente para se ter uma ideia, foi feita uma busca da palavra 'dilurimento' no Google. Obteve-se como resposta 6 (seis) páginas e um total de 87 (oitenta e sete) ocorrências com os mais variados sentidos: diarréia; desarranjo; revertério intestinal, angústia que comprime o peito, dor de barriga, mialgia generalizada etc.

3"The purpose of controlled vocabularies is to provide a means for organizing information. Through the process of assigning terms selected from controlled vocabularies to describe documents and other types of content objects, the materials are organized according to the various elements that have been chosen to describe them (ANSI/NISO, 2005, p. 10). 
O léxico das comunidades indígenas do Ceará na designação de doenças: reflexões para a construção de vocabulário controlado
Virginia Bentes Pinto; Henry de Holanda Campos; Maria do Socorro Aragão; Cristina da Costa Ribeiro

Nesse exemplo fica evidente que não há compreensão unívoca. Justamente por isso é que se considera a necessidade de construção de vocabulários controlados, não mais somente com a terminologia das linguagens de especialidades, porém, com o léxico das comunidades ou grupos sociais a serem disponibilizados nesse ambiente. Morched (2010, p. 51) chama atenção para esse fato dizendo ser necessário que se repense os novos vocabulários controlados em combinações semânticas, pois

À medida que a tecnologia [digital] de informação e comunicação está se expandindo dia a dia, é essencial acessar essas informações de forma mais fácil e eficiente. A heterogeneidade semântica é o principal obstáculo para a facilidade de extração de informações, que está crescendo no dia a dia, já que o banco de dados de vocabulários está ficando maior. [...] No entanto, o problema não é somente navegar nas páginas, mas também garantir a qualidade de conteúdo de sites da Web.

Nessa mesma linha, Moreiro González (2011) apresenta uma análise das mudanças ocorridas na construção de VC visando à representação, organização e recuperação da informação. Para esse autor, saímos de uma ideia positivista para uma pós-moderna e nós denominamos de passagem do paradigma positivista para o paradigma dialético, na perspectiva de construção do vocabulário controlado, conforme exposto no Quatro 1.

Quadro-1. Mudança do paradigma positivista para o dialético no âmbito do vocabulário controlado

\begin{tabular}{|l|l|}
\hline Paradigma positi vista & Paradigma dialético \\
\hline $\begin{array}{l}\text { Pautado nas categorias universais, formas } \\
\text { apriorísticas de representação }\end{array}$ & $\begin{array}{l}\text { Considera a linguagem a partir de sua função } \\
\text { comunicativa }\end{array}$ \\
\hline $\begin{array}{l}\text { Pauta-se, predominantemente, nas relações } \\
\text { hierárquicas em u ma perspectiva ta xonômica }\end{array}$ & $\begin{array}{l}\text { Sustenta-se predominantemente nas relações } \\
\text { associativas }\end{array}$ \\
\hline Percebe o lé xico como no menclatura ou ta xono mia & Observa o cenário da situação do discurso (semiót ica) \\
\hline $\begin{array}{l}\text { Considera a linguagem em u ma perspectiva } \\
\text { padronizada - "co municação inequívoca" }\end{array}$ & $\begin{array}{l}\text { Entende o documento a partir de sua 'função } \\
\text { comunicativa' }\end{array}$ \\
\hline $\begin{array}{l}\text { Busca a precisão, objetividade e clareza da } \\
\text { linguagem }\end{array}$ & $\begin{array}{l}\text { Considera que o indivíduo é que constrói o sentido } \\
\text { das cois as e objetos do mundo }\end{array}$ \\
\hline $\begin{array}{l}\text { Segue o modelo das ciências formais ignorando a } \\
\text { complexidade do discurso das Ciências Hu manas }\end{array}$ & $\begin{array}{l}\text { Co mpreende o documento em u ma perspectiva do } \\
\text { modelo léxico }\end{array}$ \\
\hline $\begin{array}{l}\text { Defende o substantivo como forma de representação } \\
\text { privilegiada }\end{array}$ & Entende o léxico pró ximo da linguagem natural \\
\hline
\end{tabular}


O léxico das comunidades indígenas do Ceará na designação de doenças: reflexões para a construção de vocabulário controlado
Virginia Bentes Pinto; Henry de Holanda Campos; Maria do Socorro Aragão; Cristina da Costa Ribeiro

Fonte: Adaptado de Moreiro González, J. Linguagens documentárias e vocabulários semânticos para Web. Salvador: UFBA, 2011.

Conforme a ANSI/NISO (2005) - Z39.19-2005, a necessidade de criar vocabulários controlados justifica-se ao menos por duas razões:

a) Uso de duas ou mais palavras ou termos para representar um único conceito: agitação no coração = batedeira e arritmia; curuba = pereba, ranhã e micose; lado esquecido = braço esquecido, ramo, paralisia de Bell e hemiplegia;

b) Palavras com a mesma ortografia podem representar diferentes conceitos: constipado (nariz entupido); constipado (prisão de ventre).

A ANSI/NISO (2005) - Z39.19-2005 e Smit; Kobashi (2003) determinam que na construção de vocabulário controlado deve-se observar três princípios básicos: definir o alcance, ou significado de termos; estabelecer relacionamentos semânticos que podem ser de três níveis: hierárquicos, associativos e de equivalência; distinguir os homógrafos. Outro aspecto a ser levado na construção de VC é a questão da interoperabilidade cujo alcance está intimamente relacionado aos tipos de usuários e suas necessidades específicas e conflitantes. Para tanto, a ANSI/NISO (2005) observa estes fatores conforme o Quadro 2.

Quadro-2: Necessidades de interoperabilidade nos VC

\begin{tabular}{|l|l|}
\hline Quem & Necessidades \\
\hline Pesquisadores & $\begin{array}{l}\text { Metapes quisa de múltip los recursos de conteúdo } \\
\text { usando o vocabulário de consulta preferido do } \\
\text { pesquisador }\end{array}$ \\
\hline Indexadores & $\begin{array}{l}\text { Indexação de conteúdo em um domínio usando o } \\
\text { vocabulário controlado de outro domínio }\end{array}$ \\
\hline Produtores e Detentores de Conteúdo & $\begin{array}{l}\text { Fusão de duas ou mais bases de dados que foram } \\
\text { indexadas usando diferentes vocabulários controlados }\end{array}$ \\
\hline $\begin{array}{l}\text { Comunidade de Usuários, Indexadores e } \\
\text { Produtores de Conteúdo }\end{array}$ & $\begin{array}{l}\text { Fusão de dois ou mais vocabulários controlados } \\
\text { para formar um novo que abrangerá todos os } \\
\text { conceitos e termos contidos nos originais }\end{array}$ \\
\hline $\begin{array}{l}\text { Comunidade de usuários Multilíngues e } \\
\text { Organizações Mundiais }\end{array}$ & $\begin{array}{l}\text { Multilinguagem de busca e recuperação da } \\
\text { informação }\end{array}$ \\
\hline
\end{tabular}

Fonte: ANSI/NISO - Z39.19-2005 (R2010). Guidelines for the Construction, Format, and Management of Monolingual Controlled Vocabularies.

Entretanto, mesmo com as inúmeras possibilidades dos vocabulários controlados, conforme Ménard (2008, p. 3) eles "[...] também apresentam certas fraquezas, a principal delas é representar os conceitos de forma artificial". Em realidade, constata-se que"[...] a maioria dos vocabulários controlados incluem termos linguisticamente corretos, mas esses termos 
geralmente são pouco utilizados pelos indivíduos na vida cotidiana ". Essa passagem de texto vem ao encontro da pesquisa ora apresentada, que busca chamar atenção para a necessidade de se pensar a estruturação e organização de VC em uma outra perspectiva, aquela da preservação da memória e do patrimônio cultural dos léxicos no âmbito da nominação das doenças na esfera das comunidades indígenas cearenses.

Essas reflexões levam-nos a defender que a construção de vocabulários se adotando o léxico é de fundamental importância para a manutenção do patrimônio e da memória cultural das comunidades e grupos sociais e contribuem também para a comunicação de culturas diferentes, sejam do ponto de vista antropológico ou profissional, como é o caso dos povos indígenas e os médicos.

\section{Material e Método}

Conforme pode ser observado ao longo desse artigo, o objeto desta pesquisa é a construção de um vocabulário controlado com o léxico presente nos discursos das comunidades indígenas pesquisadas para nominar as doenças e que consideramos como elementos fundamentais para a construção do vocabulário aqui proposto. Esclarecemos que nossa intenção não é um trabalho linguístico, necessariamente, porém, em alguns momentos tivemos que pedir apoio a essa disciplina para podermos nos apropriar de conceitos-chave para nossa pesquisa.

Em que concerne ao método de sustentação para nossas análises, pautamo-nos na teoria funcionalista defendida por Bates (apud NEWMEYER, 2000, p. 24) que defende "[...] a concepção de que a língua é um instrumento de interação social, e ao linguista compete a tarefa de investigar o modo como os falantes se comunicam pela língua". Por sua vez, Martinet (1974, p. 14) argumenta que

Una lengua es un instrumento de comunicación con arreglo al cual la experiencia humana se analiza, de modo diferente en cada comunidad, en unidades dotadas de un contenido semántico y de una expresión fónica.

Aliás, "[...] tudo o que [o homem] sente, o que ele percebe, o que ele compreende em todos os momentos de sua vida" se constitui em suas experiências (MARTINET apud NEVES, 2004, p. 2).

Além desse aspecto Azeredo (2002, p. 17-18, seção 5), defende o funcionalismo na perspectiva de função simbólica da linguagem ao dizer tal função "[...] é a responsável pela relação entre o indivíduo e o conjunto de suas experiências da realidade". Ele explica ainda que a língua "[...] não é apenas um meio de comunicação; ela é, antes de tudo, um sistema 
O léxico das comunidades indígenas do Ceará na designação de doenças: reflexões para a construção de vocabulário controlado
Virginia Bentes Pinto; Henry de Holanda Campos; Maria do Socorro Aragão; Cristina da Costa Ribeiro

de categorias que permite ao homem organizar o mundo em uma estrutura dotada de sentido".

Para os propósitos desta pesquisa, também utilizamos as fontes primárias e secundárias cujo escopo é dedicado aos nomes populares de doenças ou ao léxico popular, quais sejam: Dicionário de Medicina Popular (João Conrado Cavalcante da Ponte; José Olimar Carneiro Filho), Mediquês: o falar nordestino, na consulta médica (Gisleno Feitosa); Nomes e expressões vulgares da medicina no Ceará (Eurípedes Chaves Júnior), Novo dicionário de termos e expressões populares (Tomé Cabral) e também na 10a edição da Classificação Estatística Internacional de Doenças e Problemas Relacionados com a Saúde, conhecida como CID-10, disponível em http://www.datasus.gov.br/cid10/V2008/cid10.htm.

Os loci da pesquisa foram constituídos pelas seguintes comunidades indígenas: Tapebas, Pitaguarys e Jenipapos-Kanindé. O povo Tapebahabita a localidade denominada Área Indígena Tapeba, zona rural da cidade de Caucaia, região metropolitana de Fortaleza, Ceará. Conforme o censo de 2010, a população dessa comunidade é constituída por 8.010 habitantes. A comunidade dos Pitaguarys é constituída pelas aldeias Santo Antônio, Horto, Olho D’Água localizadas no município de Maracanaú, e a aldeia Monguba, em Pacatuba, além de outros povos que habitam Maranguape. Esses municípios fazem parte da região metropolitana de Fortaleza - Estado do Ceará. A população estimada é de 4.478 indígenas. Os Jenipapos-Kanindé, por sua vez, são um povo indígena que tem suas raízes nos Payakus ou Pakajús e habitam a localidade Lagoa da Encantada, município cearense de Aquiraz, região que faz parte da Grande Fortaleza. Eles conservam sua cultura por meio da oralidade - contação de histórias, rodas de conversa e a dança (Toré).

Os participantes entrevistados foram: a Pajé e mais dois membros dos Tapebas; três representantes Pitaguarys, o Pajé e a cacique- a primeira mulher nomeada com esse título, no Brasil, foram os entrevistados da comunidade dos Jenipapos-Kanindé. Ressaltamos que as pessoas que nos receberam estão entre as lideranças das comunidades e representam as "vozes e falares" dos mais antigos, ou seja, seus anciãos: pajés, caciques, lideranças comunitárias e seus filhos e filhas.

Antes das entrevistas, explicamos aos participantes o objetivo da pesquisa e esclarecemos que eles poderiam falar livremente sobre os nomes das doenças com que as comunidades se confrontavam ou ainda aqueles que eles se lembrassem. Explicamos também que, quando terminassem, apresentaríamos vários nomes que já tínhamos mapeado nas fontes para saber se eles conheciam ou se lembravam de algum.

As entrevistas foram anotadas no caderno de campo, pois, como nosso interesse era mapear os nomes populares das doenças, não nos preocupamos em gravar. As entrevistas ocorreram nas comunidades 
citadas, nas residências dos entrevistados. Nessa etapa, não foi nossa intenção restringir o falar dos entrevistados e dirigir suas respostas exclusivamente para os termos que designassem popularmente as doenças, uma vez que, em se tratando de léxico, é sabido que sua construção e utilização, além da riqueza, mesclam-se os contextos em que são aplicados. Assim, procuramos ouvir suas histórias e 'capturar' mensagens que nos elucidassem acerca de expressões guardadas na memória mais remota possível e, cuja exposição verbal somente é possível quando o locutor se sente confortável o suficiente para expressarse de forma natural e sincera.

Os corpora utilizados nesta pesquisa foram constituídos pelas palavras obtidas nas entrevistas realizadas com os representantes de liderança dessas comunidades e cotejadas com as palavras mapeadas nas fontes documentais especializadas dedicadas ao léxico e na CID-10. A organização dos dados coletados foi realizada observando-se as seguintes etapas: digitação, em uma tabela, de todas as palavras obtidas nas entrevistas, separadas por comunidade; exclusão de palavras e expressões não consideradas como nomes de doenças, após o cotejamento com as fontes especializadas; verificação de palavras semelhantes na pronúncia e significado entre as comunidades; verificação de palavras semelhantes na pronúncia, mas com significados diferentes; verificação de diferentes pronúncias, mas com significados semelhantes. Com relação à ortografia, procuramos manter a forma como as lexias apareceram nos falares dos participantes da pesquisa, mesmo que em algumas comunidades elas se diferenciassem. Essa decisão deu-se para que fosse possíveldefinir o alcance do nosso vocabulário, ou significado de termos, estabelecer relacionamento de equivalências no tocante a sinonímia e quase sinonímia e estabelecer as relações associativas e distinguir os homógrafos. Ainda, no tocante àsrelações associativas e de equivalência, também adotamos a terminologia da CID-10.

Para a construção do Vocabulário Controlado de Nomes Populares de Doenças (VCNPD), adotamos as recomendações da ANSI/NISO (2005) Z39.19-2005 (R2010) e Smit; Kobashi (2003), observando-se os três princípios básicos:

Definição do alcance, ou significado de termos: Abrange todas as regras para a construção do vocabulário controlado. Do ponto de vista sintático, a seleção e o formato do léxico das comunidades investigadas bem como a adoção de nomes, tanto no singular, quanto no plural, conforme a Norma ISO 2788.

b) Estabelecimento dos relacionamentos: Podem ser de equivalência no tocante à sinonímia e quase sinonímia, associativas e de hierarquias. As relações hierárquicas evidenciam que, no referente às enfermidades, elas podem se apresentar conforme a divisão anatômica do 
O léxico das comunidades indígenas do Ceará na designação de doenças: reflexões para a construção de vocabulário controlado
Virginia Bentes Pinto; Henry de Holanda Campos; Maria do Socorro Aragão; Cristina da Costa Ribeiro

corpo humano. No contexto da hierarquia, Harpring (2016, p. 170) acrescenta a Padronização de Relacionamentos Hierárquicos

de forma consistente e de acordo com uma lógica geral em todo o vocabulário. Cada subconjunto de termos mais específicos agrupados sob um termo mais genérico deve ser independente $e$ com significado mutuamente exclusivos em relação a outros subconjuntos.

Assim, "todos os registros na mesma ramificação da hierarquia devem referir-se à mesma classe de coisas, ações, características ou outros temas". Por exemplo, pode-se pensar em hierarquias de nomes populares de doenças a partir da anatomia humana.

c) Distinção de homógrafos: Predicar as palavras que têm a mesma grafia, porém, com significados diferentes.

Além desses aspectos, Harpring (2016, p. 170) complementa ser necessário especificar acerca da exibição de um Vocabulário Controlado: nesse aspecto, deve-se definir a escolha dos campos ou subcampos e o modo como os dados são apresentados aos diferentes usuários.

Entretanto, mais uma vez, frisamos que o VCNPD não tem a intenção de ser empregado em uma perspectiva de representação, organização e recuperação da informação referente a fontes documentais, porém, visa favorecer a comunicação entre os sujeitos dessas comunidades e os profissionais de saúde no contexto das ações de cuidados do paciente, bem como na perspectiva da preservação da memória do léxico das comunidades pesquisadas.

\section{Análise dos dados e discussão dos resultados}

O valor do léxico popular na designação das doenças, além de seu caráter de aproximação e de facilitador entre a linguagem comum e a de especialidade, também se mostra como instrumento de memória. Isso se deve ao fato do léxico se constituir no conjunto de todas as palavras de uma língua e, portanto, em manifestações concretas utilizadas nos processos de comunicação dos indivíduos de uma comunidade ou grupo social. Assim, neste capítulo, apresentamos e analisamos os dados retirados dos corpora da pesquisa, qual sejam, aquelas palavras mapeadas a partir das entrevistas realizadas nas comunidades indígenas Tapebas, Pitaguarys e Jenipapos-Kanindé e ratificadas nas fontes populares especializadas.

A estruturação dessa análise dos dados segue os objetivos específicos da pesquisa, e foram pensadas nas seguintes categorias: mapeamento do léxico coletado nas comunidades; cotejamento dos nomes populares das doenças colhidos nas entrevistas com aqueles 
O léxico das comunidades indígenas do Ceará na designação de doenças: reflexões para a construção de vocabulário controlado
Virginia Bentes Pinto; Henry de Holanda Campos; Maria do Socorro Aragão; Cristina da Costa Ribeiro

mapeados nas fontes populares especializadas; construção do protótipo do VCNPD, apoiando-nos na ANSI/NISO (2005) - Z39.19-2005 (R2010) e Smit; Kobashi (2003), estabelecendo-se as relações com as fontes populares especializadas e a CID-10.

\section{a) Mapeamento do léxico coletado nas comunidades}

Nossa intenção nessa categoria foi capturar o máximo de palavras do léxico das comunidades pesquisadas de modo que tornasse possível a construção dos corpora representativos de nomes populares de doenças que elas conhecem. Assim, foram mapeadas 379 (trezentas e setenta e nove) palavras coletadas nas comunidades indígenas investigadas. Após a exclusão daquelas que não se referiam a nomes de doenças, resultaram 355 (trezentas e cinquenta e cinco) palavras válidas com as quais eles se confrontam ou ainda, aquelas que eles lembraram os nomes durante a entrevista. Apresentaram-se no quadro 3 um exemplo dos léxicos mapeados nas comunidades indígenas Tapebas, Jenipapos-Kanindé e Pitaguarys.

Quadro-3.Alguns nomes populares das doenças, sintomas e sina is mapeados nas comunidades indígena dos Tapebas, Jenipapos-Kanindé e Pitaguarys.

\begin{tabular}{|c|c|c|c|}
\hline \multicolumn{4}{|c|}{ NOMES POPULARES DE DOENÇAS } \\
\hline Abalado & Doença dói & Mordrongo & Quebradeira no corpo \\
\hline Abirobado & Doenças inferiores & Morfético & Quebramento \\
\hline Açucar no sangue & Dor de ouvido & Morragia & Quebrante \\
\hline Agitação no coração & Dor na anca & Morróima & Queimadeira \\
\hline Àgua no joelho & Dor nas cadeira & Mula & Rachadura \\
\hline Aguaceiro na boca & Dor no pé na barriga & Murrinha & Raladura \\
\hline Aloja & Dor no percoço & Nariz entupido & Rama \\
\hline Amarelo & Dor nos quadris & Nervo torto & Ramo \\
\hline Amarelo empombado & Dor nos quartos & Nó na tripa gaiteira & Ranhã \\
\hline Andaço & Dordoi & Nó nas tripas & Remela \\
\hline Aplética & Dormença & Oiváirio de mulher que desce & Requen gado \\
\hline Arrocho no peito & Enxaqueta & Olho atravessado & Rermela \\
\hline Arroto choco & Escurrimento & Olho estufado & Rumitar \\
\hline Assadura & Esolfo ferido & Osso rendido & Russara \\
\hline Atrofiando & Esporão de galo & Osvário descido & Samorréia \\
\hline Atrufiando & Esquele da maçonaria & Ozáime & San gue grosso na pele \\
\hline Babice & Estalecido & Pampa & Sapinho \\
\hline Barriga d'água & Estilicido & Pança inflamada & Sarna \\
\hline Baticum & Estirado de dor & Pano branco & Sezão \\
\hline Berruga & Estombo alto & Pano preto & \begin{tabular}{|l|} 
Sifi \\
\end{tabular} \\
\hline
\end{tabular}


O léxico das comunidades indígenas do Ceará na designação de doenças: reflexões para a construção de vocabulário controlado
Virginia Bentes Pinto; Henry de Holanda Campos; Maria do Socorro Aragão; Cristina da Costa Ribeiro

\begin{tabular}{|c|c|c|c|}
\hline Bexiga rasa & Estombo ferido & Papa & Suado \\
\hline Bichiga & Estombo inchado & Papeira & Terentado do juízo \\
\hline Bico de papagiao & Estombo sujo & Papoca & Teriça \\
\hline Bixiga & Fanhoso & Papoquinha & Teto \\
\hline Boqueira & Farnizim no juízo & Passamento & Tinideira no ouvido \\
\hline Brotoeja & Farta de forgo & Pataca & Tiriça \\
\hline Bucho inchado & Febe & Pavio curto & Tisgo \\
\hline Bucho quebrado & Ferida braba & Pé de bolão & Tísica \\
\hline Caganeira & Gastura & Pé enrolado & Tisico \\
\hline Calombo & Goela doendo & Pé inchado & Toda upada \\
\hline Cansaço & Gorguminhos & Pé lascado & Tomorróse \\
\hline Capiongo & Gota serena & Pé raso & Tossa braba \\
\hline Carneubana & Grugumim & Pé-chato & Tosse braba \\
\hline Caroço & Gurgumim & Pé-de-quenga & Tosse de cachorro \\
\hline Cataraca & Impingem & Pedras nos rins & Trambose \\
\hline Catarro na cabeça & Incriquilhado & Peito chiando & Tremedeira \\
\hline Cavalo de crista & Intiriça & Peito piando & Tremilique \\
\hline Cerebro fraco & Isipela & Pelético & Três sol \\
\hline Chanhã & Landa & Perdeu o forgo & Trimilique \\
\hline Chiado no peito & Landra & Perdeu o incenso & Unheiro \\
\hline Cifra & Leprento & Perdeu os sentidos & Urça \\
\hline Congestão & Língua grudada & Pereba & Urina presa \\
\hline Conjutivista & Lombriga & Perna de mondrongo & Útero emborcado \\
\hline Constipação & Lumbinho & Pesadero & Vazando pelo pito \\
\hline Coração açurelado & Mal jeito & Pilora & Veia dilatada \\
\hline Corpo quebrado & Mal olhado & Piloura & Veia quebrada \\
\hline Curta da vista & Maleita & Pinta no corpo & Vermêia \\
\hline Curuba & Mancha na pele & Pipocado & Vermelhão \\
\hline Defruço & Mancha no pulmão & Pira & Vertige \\
\hline Defruz & Maria preta & Popoca & Vista curta \\
\hline Defurço & Mijar pela bunda & Pósta de catarro & Volva \\
\hline Desfalecer & Mijar pelo pito & Prisão de urina & Zambeta \\
\hline Desmentidura & Mijo preso & Privado & Zanolho \\
\hline Difruço & Mirose & Privamento & Zipela \\
\hline Disenteria & Mocomba & Pulga de bicho & Zipelão \\
\hline Doença do mundo & Mocotó inflamado & Pulga de cachorro & Zói trocado \\
\hline Doença braba & Moleira aberta & Pulmão man chado & Zuada nos ouvidos \\
\hline Doença da mulher & Moleira funda & Pustema & Zurumbático \\
\hline Doença do mundo & Mordrongo & Puxado & \\
\hline
\end{tabular}

\section{Fonte: Dados da pesquisa}


Olhando esses achados resgatados durante as entrevistas, compreende-se que o léxico se constitui em um conjunto de unidades sígnicas que as comunidades indígenas utilizam tanto em seus processos de comunicação como também visando compreender o mundo no qual estão inseridas. Durante as entrevistas e as observações, percebemos quanto os participantes buscavam confirmar a fala do outro, inclusive fazendo certas correções nas pronúncias dos nomes das doenças ou se manifestando sobre a ocorrência ou não da enfermidade na comunidade, ou, ainda, corrigindo se aquilo que fora dito que era tal doença era mesmo. Por exemplo, um dos participantes se expressou "[...] dordói que a gente chama [...]". Tem o 'dordói' que é pra tudo. "Não, mãe, tem aquela outra que é carne crescida". "Aquela lá não é dordói, é carneubana" (Diálogos entre a cacique e o pajé- Jenipapos-Kanindé). Esses achados vêm ao encontro do entendimento de Biderman (2001, p. 9) ao afirmar que o léxico como um "[...] saber partilhado que existe na consciência dos falantes de uma língua, constitui-se no acervo do saber vocabular de um grupo socio-linguístico-cultural". Logo, por meio dele, pode-se conhecer a cultura de determinado povo, "[...] porque ele é uma janela aberta que transparece toda história de uma sociedade".

De posse dessas descobertas, percebemos que havia necessidade de trazer à baila e destacar algumas observações que foram percebidas ao longo da construção do banco de dados. Para tanto, observamos os seguintes aspectos e que exemplificamos no Quadro -4.

Quadro-4 Observações capturadas ao longo das entrevistas.

\begin{tabular}{|c|c|c|c|c|}
\hline \multirow[t]{2}{*}{ Categorias } & \multicolumn{4}{|c|}{ Comunidades Indígenas } \\
\hline & $\begin{array}{l}\text { Jenipapos- } \\
\text { Kanindé }\end{array}$ & Pitaguarys & Tapebas & $\begin{array}{c}\text { Terminol ogia } \\
\text { Científica/CID } 10\end{array}$ \\
\hline $\begin{array}{l}\text { Palavras semelhantes na } \\
\text { pronúncia e significado } \\
\text { entre as comunidades. }\end{array}$ & Ramo & Ramo & Ramo & He miplegia \\
\hline \multirow[t]{2}{*}{$\begin{array}{l}\text { Palavras semelhantes na } \\
\text { pronúncia, mas com } \\
\text { significados diferentes. }\end{array}$} & $\mathrm{X}$ & $\begin{array}{l}\text { Bucho inchado } \\
\text { (Gases na barriga) }\end{array}$ & $\begin{array}{c}\text { Bucho inchado } \\
\text { (Hérnia) }\end{array}$ & $\begin{array}{l}\text { Dilatação aguda do } \\
\text { estômago, corruptela } \\
\text { de hérnia para os } \\
\text { Tapebas. }\end{array}$ \\
\hline & & & & $\begin{array}{l}\text { Flatulência e } \\
\text { afecções correlatas, } \\
\text { corruptela de gases } \\
\text { estomacais para os } \\
\text { Pitaguarys. }\end{array}$ \\
\hline $\begin{array}{l}\text { Palavras diferentes } \text { na } \\
\text { pronúncia, } \\
\text { significados } \\
\text { sigemelhantes. }\end{array}$ & $\begin{array}{l}\text { Difruço } \\
\text { (Gripe) }\end{array}$ & $\begin{array}{l}\text { Defruiz, Defruço } \\
\text { (gripe) }\end{array}$ & $\mathrm{X}$ & Influenza \\
\hline
\end{tabular}

Fonte: Dados da pesquisa empírica 
Os dados da pesquisa ratificam a importância do léxico para a construção de vocabulários tendo em vista o resgate das memórias das comunidades investigadas, pois, conforme Carvalho (2009, p. 33-36), "O acervo lexical, nomeando o mundo exterior, reflete a cultura da sociedade à qual serve de meio de expressão". Ademais, "Partindo do estudo do léxico pode-se explicar a vida de uma sociedade", razão pela qual, faz-se necessária a sua manutenção e divulgação para além das comunidades. Desse modo, se houver uma preocupação do levantamento dos léxicos, certamente eles preservarão "a visão de mundo de uma determinada comunidade e, por isso, possuem um caráter acentuadamente social, cultural e histórico", conforme expressa (XAVIER, 2011, p. 97).

Conforme já mencionamos várias vezes ao longo deste artigo, e nos apoiando em Duarte (2000), defendemos que a utilização dos nomes populares de doenças para a construção do VCNPD contribui para a manutenção do léxico, tanto do ponto de vista ativo quanto passivo. No primeiro caso, refere-se ao número de palavras usadas e registradas na memória e que são utilizadas para se comunicar no dia a dia de sua comunidade, ao passo que o léxico passivo diz respeito ao que o indivíduo compreende, ainda que não faça parte de seu cotidiano. Assim, em muitos casos os participantes expressaram nomes populares de doenças argumentando que conheciam, porém, não era usado em sua comunidade.

b) Cotejamento dos nomes populares das doenças colhidos nas entrevistas com fontes populares especializadas

Nessa categoria, construímos a matriz de cotejamento que foi elaborada com base nas entrevistas com os representantes das comunidades e também nas fontes populares especializadas. 0 cotejamento foi somente com as comunidades pesquisadas e a intenção é verificar se há semelhança entre o léxico dessas comunidades e as fontes populares consultadas. Fazendo o cotejamento entre as palavras colhidas nas entrevistas e as fontes populares, os resultados foram: 151 (cento e cinquenta e uma) repetições entre os Tapebas e as fontes. Com respeito ao cotejamento entre os Pitaguarys e as fontes, obtiveram-se 133 (cento e trinta e três) palavras coincidentes, ao passo que os nomes populares de doenças enunciados pelos Jenipapos-Kanindé e coincidentes com as fontes pesquisadas foi um total de 160 (cento e sessenta) palavras. Isso pode ser explicado justamente pelo fato dessas fontes populares serem formalmente estruturadas e, inclusive, uma servindo de fonte para outra. Tal fato nos subsidia para defendermos a utilidade do mapeamento dos nomes populares de enfermidades, afinal essa decisão, certamente, contribuirá para a manutenção das memórias desses povos e, 
consequentemente, do seu léxico. Loh; Harmon (2014, p. 49, tradução nossa)4 afirmam que "Manter a diversidade não é apenas uma questão de proteção das línguas ameaçadas de extinção e espécies em locais críticos remotos da diversidade biocultural [...]". Essa manutenção é de importância vital e "[...] também uma questão de permitir a diversidade de prosperar naquelas partes do mundo onde os seres humanos já tiveram um profundo impacto sobre a paisagem biológica e cultural, nas mais populosas regiões do planeta".

Eis aí, mais uma justificativa para se defender a construção de vocabulários adotando-se o léxico. Com essa decisão, fortalece-se a ideia de preservar o patrimônio e a memória cultural das comunidades e grupos sociais, o que resultará em melhorias também para a comunicação de culturas diferentes, sejam do ponto de vista antropológico ou profissional, como é o caso dos povos indígenas e os médicos ou outros profissionais da área da Saúde.

\section{c) Construção do protótipo do VCNPD estabelecendo-se as relações com as fontes populares especializadas e a CID-10}

Conforme já foi mencionado na seção sobre material e métodos, a construção do VCNPD pautou-se na ANSI/NISO Z39.19-2005 (R2010) e em Smit; Kobashi (2003), conforme a seguir: Definição do alcance, ou significado de termos; estabelecimento dos relacionamentos de equivalência no tocante à sinonímia e quase sinonímia e hierarquia e distinção de homógrafos.

1) Definição do alcance, ou significado de termos: o VCNPD foi construído visando facilitar o processo de comunicação entre os membros das comunidades indígenas investigadas, os médicos e a equipe multiprofissional da saúde no momento das ações de cuidado dos pacientes. Ele é constituído por um conjunto de 355 (trezentas e cinquenta e cinco) palavras simples e compostas, expondo-se alguns exemplos nos Quadros 3, 4 e 5, estabelecendo-se a exibição de vários tipos de relações entre os termos da linguagem natural e a terminologia da área da saúde. O léxico adotado usa tanto nomes no singular quanto

4 Maintaining diversity is not just a question of protecting endangered languages and species in remote hotspots of biocultural diversity such as the Amazon or New Guinea, vitally important though that is, conservation is also a matter of allowing diversity to thrive in those parts of the world where humans have already had a profound impact on the biological and cultural landscape, in the more densely populated parts of the planet. Recognizing and exploring the parallels between nature and culture, and understanding the processes that underlie their evolution, ecology and extinction, is a fi rst step towards ensuring that we can continue to inhabit a world of incredible diversity" (LOH; HARMON, 2014, p. 49). 
no plural, conforme a Norma ISO 2788. ID-10. No tocante à Nota de Escopo (NE) utilizamos a nomenclatura da CID-10.

Ex. Defruço

NE: Refere-se à 'Influenza' [gripe] com outras manifestações respiratórias devido a vírus não identificado (CID-10).

2) Estabelecimento dos relacionamentos de equivalência no tocante à sinonímia e quase sinonímia. Em que concerne às relações, no VCNPD seguimos a orientação das fontes, imediatamente anteriores, observando um modelo de registro em versão linear no sentido vertical, em que podemos visualizar os distintos níveis de subordinação. Entretanto, como nossa intenção é trazer esse vocabulário mais no sentido de comunicação entre culturas diferentes e visando à manutenção da memória, lançamos outro olhar sobre o vocabulário controlado adaptando ao caso particular do VCNPD. Assim, por exemplo, não nos preocupamos em definir nomes preferidos, pois, para os fins que nos propomos, todas as palavras podem ser utilizadas, afinal o importante é tentar evitar interferências no ato das ações de cuidado do paciente. Para melhor entendimento das 'chaves' adotadas, organizamos as relações conforme a seguir:

-Relações sinônimas e quase sinônimas: Embora a chave USE indique a preferência pelo uso do termo (palavra no caso em lide) preferido entre os vários sinônimos; a referida 'chave' não foi levada em consideração nessa perspectiva por não se tratar de termos para indexação. Porém, indicar que no processo de comunicação e com vistas à preservação da memória lexical, qualquer palavra pode ser usada. Desse modo a chave usada foi USADO TAMBÉM PARA (UTP).

Ex: Difruço

UTP- Defruz

UTP -Defurço

NE = 'Influenza' [gripe] com outras manifestações respiratórias, devida a vírus não identificado (CID-10)

Ex:Falta de Fôrgo

UTP - Perder o Fôrgo

UTP - Cansaço

NE = Dispneia, fôlego curto, ortopneia (CID-10)

-Relações Hierárquicas: evidenciam que, no referente às enfermidades, elas podem se apresentar conforme a divisão anatômica do corpo humano, ou seja, todo parte.

Termo Genérico Maior (TGM) -mostra uma palavra ou nome mais geral dentro de uma relação hierárquica.

TGM - DOENÇAS

Ex. TG - Doenças no joelho

TE - Água no joelho

$\mathbf{N E}=$ Derrame articular (CID-10) 


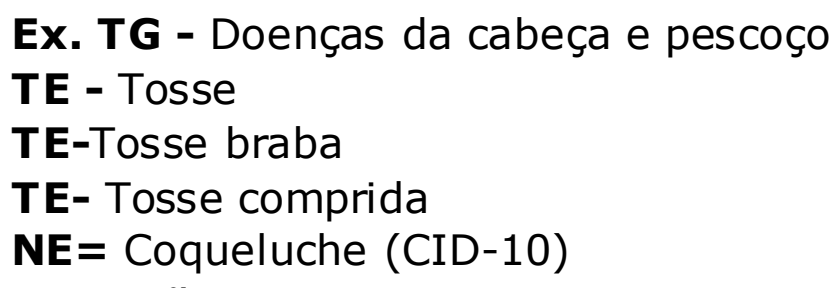

-Relações associativas: evidencia a relação entretermos que não são equivalentes nem hierárquicos, mas que estão associados semanticamente ou conceitualmente à chave TR (termo relacionado)

Ex: Conjuntivista

TR: Dordói

NE: Conjuntivite não especificada (CID-10)

Ex: Pereba

NE: Piodermite

TR: Pira

NE: Escabiose [sarna] (CID-10)

3) Distinção de homógrafos: predicar as palavras que tem a mesma grafia, porém, com significados diferentes

Ex: Constipado(Nariz entupido)

NE: Outros transtornos do nariz e dos seios paranasais (CID-10)

Constipado (Prisão de ventre)

NE: Constipação/Obstipação Intestinal (CID-10)

\section{Algumas reflexões conclusivas}

Os achados da pesquisa evidenciam que, embora as comunidades pesquisadas tenham suas gêneses na própria história do Brasil, ainda assim, conservam o seu léxico como representações mentais da realidade, embora que também já tenham incorporado os termos das linguagens de especialidades do contexto da saúde.

A pesquisa nos possibilitou conhecer e aprender um pouco sobre as linguagens das comunidades indígenas com as quais dialogamos. Passamos a conhecer um léxico que mesmo muito próximo dos pesquisadores não se manifestava tão evidente.

No estudo empírico feito por meio das entrevistas, das observações e também da análise das fontes, percebemos que há variantes léxicas dos nomes populares que as comunidades investigadas usam para nomear as doenças.

Infere-se, ainda, que em razão da institucionalização dos prontuários eletrônicos do paciente (PEP), a construção de vocabulários com o léxico das comunidades, sejam indígenas ou outras, a exemplo dos povos que habitam o sertão nordestino e as regiões ribeirinhas ou zonas rurais brasileiras, poderá trazer grandes contribuições para diminuir as interferências na comunicação entre a equipe multiprofissional da saúde e 
o paciente. Para tanto, tal vocabulário precisa estar inserido nos sistemas de informação das organizações de saúde a fim de que venha a ser consultado no momento dos atendimentos ao paciente. Finalmente, entendemos a necessidade de manutenção da 'etnossaúde', construindose vocabulários controlados a partir do léxico das comunidades de modo geral e, particularmente, no que se refere aos povos indígenas. Não podemos mais ignorar o léxico das comunidades.

\section{Agradecimentos}

As autoras e o autor deste artigo agradecem o apoio do Conselho Nacional de Desenvolvimento Cientifico e Tecnológico (CNPQ) mediante ao financiamento do Projeto Universal-Processo-456624/2014-7. Igualmente, deixamos a nossa gratidão às comunidades indígenas Tapebas, Pitaguarys e Jenipapo-Kanindé, que possibilitaram a realização das entrevistas.

\section{Referências}

ANSI/NISO Z39.19-2005 (R2010).Guidelines for the Construction, Format, and Management of Monolingual Controlled Vocabularies.

AZEREDO, José Carlos de.Fundamentos de Gramática do Português. Rio de Janeiro: Jorge Zahar, 2002.

BIDERMAN, Maria Tereza Camargo. Aestrutura mental do léxico. In: F. S. Borba. (Org.). Estudos de filologia e linguística em homenagem a Isaac Nicolau Salum. São Paulo: T. A. Queiroz, Ed. Universidade de São Paulo, 1981 , p. $132-145$.

CABRAL, Tomé. Novo dicionário de termos e expressões populares. Fortaleza: Edições UFC, 1982.

CARVALHO, N. Acervo lexical. In: CARVALHO, N. Empréstimos linguísticos na língua portuguesa. São Paulo: Cortez, 2009.

CHAVES JUNIOR, Eurípedes. Nomes e expressões vulgares da medicina do Ceará. Fortaleza: Centro Médico Cearense, 1985.

CURRIER SARAH, Lorna M. CAMPBELL, Helen Beetham. Pedagogical Vocabularies Review, JISC Pedagogical Vocabularies Project, Final Draft, 23 rd December 2005.

DUARTE, I. Língua portuguesa.Instrumentos de análise.Lisboa: Universidade Aberta, 2000. 
FEITOSA, Gisleno. Mediquês: o falar nordestino, na consulta médica.

Teresina: Academia Piauiense de Letras, 2017.

HARPRING, Patricia. Introduction to controlled vocabularies: terminology for art, architecture, and other cultural works. Los Angeles: Getty Publications, 2010. Disponível em:

http://d2aohiyo3d3idm.cloudfront.net/publications/virtuallibrary/1606060 18X.pdf. Acesso em: 12 mar. 2018.

HARPRING, Patricia. Introdução aos vocabulários controlados:

terminologia para arte, arquitetura e outras obras culturais [Em linha]. São Paulo.Secretaria da Cultura do Estado de São Paulo:Pinacoteca de São Paulo; ACAM Portinari, 2016. Disponível em: https://issuu.com/sisemsp/docs/vocabul rios controlados - digital. Acesso em: 10 maio. 2018.

HEDDEN, Heather. Controlled vocabularies, thesauri, and taxonomies.The Indexer. [S.I], v. 26 n. 1, March 2008.

LOH, J; HARMON, D. Biocultural diversity: threatened species, endangered languages. WWF Netherlands, Zeist the Netherlands. 2014.

MARTINET, André. Éléments de linguistique générale. Madrid: O Editorial Gredos, 1974.

MÉNARD, Elaine. Étude sur l'influence du vocabulaire utilisé pour l'indexation de l'image numérique sur le repérage en contexte multilingue. Montreal : UDM, 2008.

MOREIRO GONZÁLEZ, José Antonio. Evolução ontológicas das linguagens documentárias: relato de uma experiência de curso organizado conjuntamente para o DT/SIBI-USP e o PPGCI/ECA. In CID: Revista de Ciência da Informação e Documentação, São Paulo, v. 2, n. 1, p. 143-164, 2011.

MORSHED, Ahsan-ul. Aligning controlled vocabularies for enabling semantic matching in a distributed knowledge management system. Trento: International Doctorate School in Information and Communication Technologies DIT, 2010.

NEVES, M.H.M. A gramática funcional. São Paulo: Martins Fontes, 2004

NEWMEYER, F. J. Language form and language function. London: MIT Press, 2000.

OMS.Classificação estatística internacional de doenças e problemas relacionados com a saúde(CID-10). Disponível em: 
http://www.datasus.gov.br/cid10/V2008/cid10.htm. Acesso em: 12 mar. 2018.

PAULA, Maria Helena de.Rastro de velhos falares: léxico e cultura no vernáculo catalano, 2007. 521f. Tese (Doutorado em Linguística e Língua Portuguesa) - Universidade Estadual Paulista (UNESP), Faculdade de Ciências e Letras, Araraquara, São Paulo, 2007.

PONTE, João Conrado Cavalcante da; CARNEIRO FILHO, José Olimar. Dicionário de Medicina Popular. Fortaleza: Ed. Premius, 2000.

SMIT, Johanna Wilhelmina; KOBASHI, Nair Yumiko. Como elaborar vocabulário controlado para aplicação em arquivo. São Paulo: Arquivo do Estado, Imprensa Oficial, 2003. 56 p. (projeto como fazer, 10).

XAVIER, Vanessa Regina Duarte. Conexões léxico-culturais em manuscritos setecentistas. ReVEL. [S.I], v. 9, n. 17, 2011.Disponivel em: http://www.revel.inf.br/files/artigos/revel 17 conexoes lexico culturais em manuscritos setecentistas.pdf.Acesso em 11 jan. 2018. 